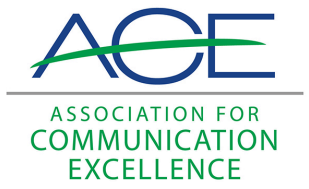

Journal of Applied Communications

\title{
Should livestock images provide historical reference or modern reality? An examination of the Influence of Livestock Communication on Attitude.
}

Joy N. Rumble

The Ohio State University

Tiffany M. Rogers-Randolph

University of Florida

Emily B. Buck

The Ohio State University

Follow this and additional works at: https://newprairiepress.org/jac

Part of the Other Communication Commons

c) (1) (2)

This work is licensed under a Creative Commons Attribution-Noncommercial-Share Alike 4.0 License.

\section{Recommended Citation}

Rumble, Joy N.; Rogers-Randolph, Tiffany M.; and Buck, Emily B. (2019) "Should livestock images provide historical reference or modern reality? An examination of the Influence of Livestock Communication on Attitude.," Journal of Applied Communications: Vol. 103: Iss. 2. https://doi.org/10.4148/1051-0834.2263

This Research is brought to you for free and open access by New Prairie Press. It has been accepted for inclusion in Journal of Applied Communications by an authorized administrator of New Prairie Press. For more information, please contact cads@k-state.edu. 


\title{
Should livestock images provide historical reference or modern reality? An examination of the Influence of Livestock Communication on Attitude.
}

\begin{abstract}
The livestock industry has repeatedly struggled to effectively communicate livestock care and handling practices in order to promote awareness and acceptance. Many consumers still hold on to the historically picturesque view of production agriculture instead of the modern reality. It is necessary for the industry to identify how much is too much to tell or show consumers. Therefore, this study sought to understand the influence of two communication treatments on attitudes toward livestock care and use. Elaboration Likelihood Model (ELM) served as the theoretical framework for this study. A sample of 1,049 respondents was obtained through non-probability sampling. To fulfill the purpose of this study, the development of an online survey was informed by ELM and measured prior beliefs, personal involvement, and knowledge. An experimental treatment, consistent with persuasive communication within ELM, presented respondents with one of two images of cage-free egg laying housing and accompanying text. One image could be described as "historically picturesque" and the other as "modern reality." Attitude toward livestock care and use was measured after exposure to one of the images. Respondents held favorable prior beliefs, demonstrated neutral involvement, and answered three or less knowledge questions correctly. Respondents exposed to the modern reality treatment displayed slightly lower attitudes than those exposed to the historically picturesque treatment. The results indicated that both prior beliefs and image exposure had a significant impact on attitude, while personal involvement was not found to be significant.

\section{Keywords}

Elaboration Likelihood Model, Livestock care and use, persuasion

\section{Cover Page Footnote/Acknowledgements}

A version of this manuscript was previously presented at the Association for Communication Excellence in Agriculture, Natural Resources, and Life and Human Sciences Conference. Additionally, this study was funded by the UF/IFAS Center for Public Issues Education and supported by the USDA National Institute of Food and Agriculture, Hatch project \#1003955.
\end{abstract}




\section{Introduction}

The livestock industry has repeatedly struggled with consumer awareness and acceptance of livestock handling practices (Duncan \& Broyles, 2006; Weatherell, Treager, \& Allinson, 2003). In an effort to improve awareness and acceptance, the industry has struggled to identify how much is too much to tell or show consumers. As Dietrich (2016) said, livestock production as well as broad agricultural production is "hard and ugly" and the practices do not "look or sound attractive" (p. 1). At one time, agricultural production was more picturesque to the farm visitor or passerby. The farms were smaller and livestock grazed on green pastures under blue skies. During this time, more people were also growing their own food or getting it from someone close to them. So, despite the more picturesque production image, people were also more familiar with the processes that would enable a steer in a pasture to become steak on their dinner plate. Picturesque farms still exist today and can be seen while taking a drive in the country, but it is not likely that those small, stereotypical, and idealistic farms are the ones providing meat, eggs, or dairy to the consumer's favorite grocery store retailer. However, consumers value the picturesque images of agriculture and livestock production and in some cases still believe that the majority of livestock are raised on those picturesque farms (Goodwin, 2010; Specht, McKim, \& Rutherford, 2014).

Today livestock production in the United States is large scale, efficient, and technologically advanced (Taylor \& Field, 2004). Often, this means animals are confined within large barns to protect them from predators, disease, and weather, while also closely monitoring their health and rations (Taylor \& Field, 2004). These practices allow the livestock industry to account for half of all agriculture production and meet the rising domestic and export demand for meat (APHIS, 2010; Sterk, 2017). The modern livestock production system is not very picturesque. The image of large barns often built of concrete and steel, with thousands of animals, under artificial lighting is not visually appealing. Furthermore, most consumers only see these barns from the outside and never know or understand what is inside of them.

Communication and sociology theories tell us that we should be open and honest in our communications about livestock production practices (Carroll, 1991; Jaques, 2012; Rawlins, 2008). Additionally, important figures in the industry have called for transparency of practices and even live video feeds and tours in barns and slaughter plants (Vance, 2012). Research has also shown that communication with high levels of transparency has a positive impact on attitudes and trust toward organizations raising livestock (Goodwin, 2013). However, a recent study showed that consumers would rather look at a blank screen than a picture of modern hog housing (Bell, Norwood, \& Lusk, 2017). Consumers are willfully ignorant about livestock production and are not afraid to admit it (Bell et al., 2017). There is also a portion of the livestock industry who fears that transparency of the livestock industry opens the industry up to criticisms and regulations (Beulens, Broens, Folstar, \& Hofstede, 2005). In this study, the impact of two livestock production images (historically picturesque vs. modern reality) on attitudes toward livestock care and use were examined. This study will help to inform the ongoing debate regarding how much information should be communicated about livestock production practices.

\section{Theoretical Framework}

The instrument development and data analysis for this manuscript was informed and guided by the elaboration likelihood model (ELM). "The ELM is based on the notion that people are motivated to hold correct attitudes but have neither the resources to process vigilantly every persuasive argument nor the luxury-or apparently inclination-of being able to ignore them all" (Cacioppo, Petty, Kao, \& Rodriguez, 1986, p. 1032). ELM provides a framework to understand attitudes after 
the presentation of persuasive communication. The theory suggests that if people have the motivation and ability to process the communication they will process the information at a deep cognitive level, known as the central processing route (Petty, Brinol, \& Priester, 2009). The deep cognitive processing results in a strong and enduring attitude that is more resistant to counter persuasion. Whether the resulting attitude is positive or negative toward the communication is dependent on initial attitude toward the communication and the quality of arguments that the communication presents (Petty et al., 2009). It is possible for individuals to have the motivation and ability to process the message but fail to generate deep cognitive thoughts. In these instances, individuals would retain their initial attitude. Additionally, if an individual is lacking the motivation and/or ability to process the communication they will either retain their initial attitude or process the information peripherally (Petty et al., 2009). Peripheral processing occurs when individuals do not have the motivation or ability to process the communication, but they connect with or are attracted to a peripheral cue in the communication such as a source, word, or attractive image. Attitudes that result from peripheral processing can be negative or positive toward the communication, but they are weaker attitudes that can be changed easily and are not long lasting (Petty et al., 2009).

Historically and traditionally, ELM research has used text-based messages as the persuasive communication component and any visual components have been seen as peripheral cues (Lazard \& Atkinson, 2015). However, "mediated messages are perceived holistically; that is, all visual elements of a message-both imagery and text-are seen as one constructed unit on first impression or initial glance" (Lazard \& Atkinson, 2015, p. 10). Visual elements have also been found to have a greater influence on attitude (Griffin, 2008; Messaris, 1994). Lazard and Atkinson (2015) proposed that messages with text and visual integration would result in higher elaboration than messages with only text. In an experimental design with one group receiving a text-based message and the other group receiving an infographic, they found that higher levels of elaboration were observed among the infographic group. In conclusion, the authors reiterated the value of visuals in communication. "The prevalence of visual messages today no longer allows us to ignore the role that visual content plays in decisions to process" (Lazard \& Atkinson, 2015, p. 28).

Previous ELM research has shown repeated peripheral processing of messages in the context of agriculture and natural resources (Frewer, Howard, Hedderley, \& Shepherd, 1997; Gore, Knuth, Scherer, \& Curtis, 2008; Goodwin, 2013; Veberke, 2005). Abrams and Meyers (2012) said "most people are not motivated or highly involved with animal agriculture" (p. 64). Goodwin (2013) examined the cognitive processing of a facebook page for a livestock farm. The study consisted of an experimental design in which the personal relevance and transparency of the facebook page were manipulated. The personal relevance variable served as motivating factor within ELM. No significant difference in attitudes toward the livestock farm was found between the groups that received the high personal relevance page and those who received the low personal relevance page. Therefore, the researcher concluded that the respondents did not have the motivation to process the information and therefore participated in peripheral processing (Goodwin, 2013).

In addition to the characteristics described in ELM, image processing can also be influenced by the image itself. Culturally incongruent images have been shown to negatively influence attitudes (Zhou, Poon, \& Wang, 2015). Zhou et al. (2015) found that when images do not align with the cultural expectation of consumers, attitudes of skepticism are formed. Additionally, Zhou et al. (2015) suggest that in these instances, consumers may be using persuasion knowledge to inform their attitude. Persuasion knowledge is the awareness that one is 
trying to be persuaded (Ham, Nelson, \& Das, 2015; Zhou et al., 2015). When someone feels that they are trying to be persuaded they may ignore or provide a counterargument to the information being presented (Ham et al., 2015).

Stereotypical images have historically been used to promote consumer goods (Berg \& Söderlund, 2013). However, recent pushes for diverse representation of practices and cultures has led many industries to move away from stereotypical images. The move away from stereotypical images is viewed as risky and is known to be associated with adverse effects for industries and businesses (Berg \& Söderlund, 2013). Berg and Söderlund (2013) suggested finding a balance between stereotypical and representative images by removing any social stimuli from the images. The removal of social stimuli was found to improve attitudes (Berg \& Söderlund, 2013).

Several studies of agricultural images have been examined for their influence on consumer perception (Glaze, Edgar, Buck, Rutherford, 2013; Lundy, Ruth, \& Park, 2007; Specht \& Beam, 2017), but no known research has compared the influence on consumer attitude between stereotypical and modern agricultural production images. Specht and Beam (2017) found that agricultural stereotypes portrayed in a popular television show simplified agriculture. Similarly, Lundy et al. (2007) suggested that images portrayed in media could have short- and long-term effects on agricultural perceptions and possibly reinforce negative agricultural stereotypes. Additionally, Glaze et al. (2013) found that students discussed topics of culture, experience, and stereotypes, among others, after viewing images of rural America.

\section{Purpose and Objectives}

The purpose of this study was to understand the influence of two images on attitudes toward livestock care and use, using the ELM framework. This research will help the livestock industry understand how much to communicate to consumers about livestock practices. The objectives of the study were: 1) Describe respondents' prior beliefs, personal involvement, knowledge, and attitude toward livestock care and use; and 2) Compare predictive models to determine which ELM variables and which persuasive communication treatment have the greatest influence on attitude.

\section{Methods}

The population of interest for this study was United States residents, 18 years of age or older. A sample of 1,049 respondents was obtained through non-probability sampling. Non-probability sampling does not give all possible respondents an equal chance of participating and in this case the sample included volunteers from an opt-in market research panel (Baker et al., 2013). Qualtrics, a survey company, recruited, qualified, and incentivized the sample of respondents. Poststratification weighting was used to reduce the error and bias associated with non-probability sampling (Baker et al., 2013). Data were weighted according to the 2010 United States' Census demographics for age, race/ethnicity, and gender.

Data were collected from respondents via an online survey. The instrument development was informed by ELM and was validated by a panel of experts. The panel of experts included a social scientist, an animal scientist, and two livestock commodity organization representatives. The instrument began with a measure of prior beliefs toward livestock care and use, which served as a measure of initial attitude within ELM (Petty et al., 2009). Prior beliefs were measured using an 11-item Guttman scale, with the options of 0-Have no opinion, 1 -Do not favor, 2 - Somewhat favor, 3 -Strongly favor (Guttman, 1950). The question asked respondents to indicate their level of favorability toward a series of livestock care and use practices that covered nutrition, housing, treatment, vaccination, byproducts, identification, euthanasia, and consumption. Some of the 
statements included: Feeding livestock a nutritionally balanced diet; Vaccinating livestock against disease; and Giving livestock an ear tag for individual identification and traceability purposes. Responses to each statement were recoded to 0 - Do not favor (Have no opinion and Do not favor) and 1 - Favor (Somewhat favor and Strongly favor), according to Guttman's recommendations (Guttman, 1950). The prior beliefs statements were found to be reliable $(\alpha=.84)$. In preparation for data analysis, the prior belief responses were summated to create a count variable. Final prior belief scores could range from 0 to 11 .

Within ELM, personal involvement serves as a motivation variable (Petty et al., 2009). Personal involvement was measured using a 12-item binomial scale with the options of 1 -Yes and $0-$ No. The respondents also had the option of answering Unsure for each statement. Unsure responses were omitted from further analysis. The question asked respondents to indicate whether or not the statements were true about them. The statements gathered respondents' involvement in livestock and animal related experiences including owning livestock or pets, being involved in animal-based organizations, eating or consuming animal derived products, seeing animals at fairs or zoos, and donating money to animal based organizations. Some of the statements included: $I$ own or have owned livestock; I am a member or past member of an animal welfare or animal rights organization; and I include meat as part of my regular diet (chicken, beef, pork, or other meat). The personal involvement statements were found to have modest reliability according to Ary, Jacobs, Sorenson, and Walker $(2014 ; \alpha=.64)$. Because of the modest reliability interpretation of personal involvement conclusions should be made with caution. The statements were summated to create a count variable for data analysis. Final personal involvement scores could range from 0 to 12 .

After gathering respondents' prior beliefs and issue involvement, knowledge of livestock care and use was assessed. Knowledge is identified as an ability factor within ELM (Petty et al., 2009). Knowledge was measured using eight multiple choice questions. The knowledge questions asked respondents about different livestock care and use topics such as proper injection site, slaughter age, average production, reproduction, genetics, and byproducts. Correct responses were assigned a 1 and incorrect responses were assigned a 0 . The knowledge variable violated the assumptions of regression analysis and is therefore only included in the analysis of objective 1 .

After gathering these measures respondents were presented with an experimental treatment, which served as the persuasive communication within ELM (Petty et al., 2009). Respondents were randomly assigned to receive one of two possible treatments (historically picturesque vs. modern reality). The researchers limited the experimental design to two groups to limit the variables of influence and to ensure that the experimental groups had adequate numbers for comparison. Introducing additional images into the experimental design, perhaps of different species of livestock, different housing systems, and different accompanying descriptions could have altered the results, but it would have been difficult to tell if any differences in attitude were due to the species of animal, housing system, or descriptions. Therefore, the researcher elected to add more control to the experiment by using the same species, the same type of housing (cagefree), and similar descriptions. The added control will allow any difference in attitudes to be more confidently attributed to the difference in the historically picturesque and modern reality images. Both treatments included a visual image and accompanying text. Both images were of cage-free egg laying hen housing and the text described each image (Figure $1 \& 2$ ). The text only differed when describing whether the housing system was climate controlled. 
This image depicts cage-free housing for egg laying hens. The hens may roam around and are able to enter and exit the enclosed nesting area as they please. The hen's housing is not climate controlled.

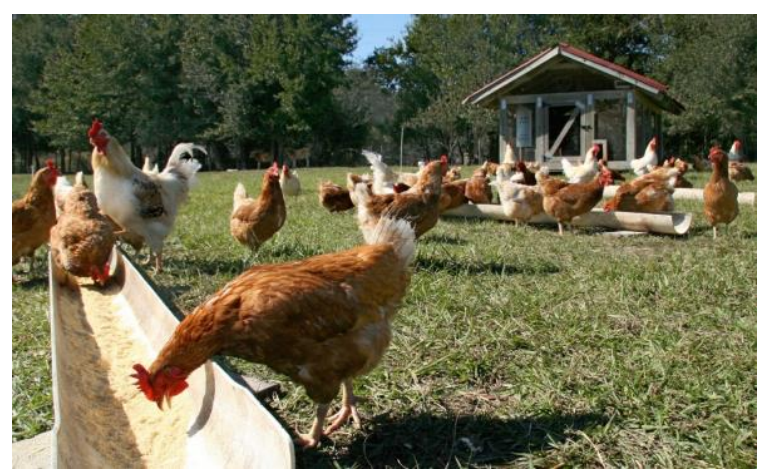

Figure 1. Historically picturesque treatment
This image depicts cage-free housing for egg laying hens. The hens may roam around and are able to enter and exit the enclosed nesting areas as they please. The hen's housing is climate controlled.

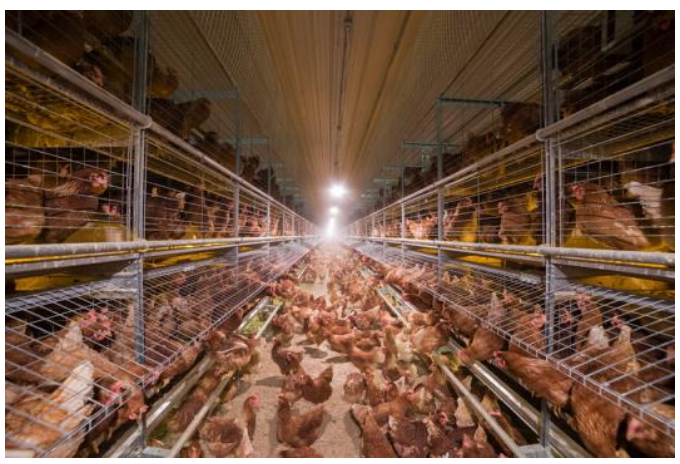

Figure 2. Modern reality treatment

After the presentation of the experimental treatment, attitude toward livestock care and use was measured. Attitude was measured on a 7-item, 5-point semantic differential scale. The respondents were presented with the statement "The care and use of livestock raised for human consumption in the United States is..." and were then asked to select a point between each set of bipolar adjectives. The adjective pairs included acceptable/unacceptable, favorable/unfavorable, bad/good, harmful/beneficial, positive/negative, unimportant/important, and progressive/regressive. Negative adjectives were assigned a 1 and positive adjectives were assigned a 5 . The attitude items were found to be reliable $(\alpha=.90)$ and were averaged to create and index.

Within the instrument there was one quality check question to ensure respondents were attentive to the survey. The question asked respondents to select definitely yes. If they did not select definitely yes, the respondents were dismissed from the survey. There was also a manipulation check incorporated into the survey. For the manipulation check, respondents had to select the image that they were presented with during the experiment. If they selected the wrong image they were dismissed from the survey. 1,049 complete and usable responses were recorded. To analyze objective 1, descriptive statistics including means and standard deviations were reported for the variables of interest. To analyze objective 2, a hierarchical regression analysis was used to determine which ELM variables had the greatest influence on attitude toward livestock care and use. Hierarchical regression was chosen in order to model the pathways suggested by ELM by adding a variable at each step. Objective 2 could have also been analyzed through stepwise regression, but rather than discovering variables of influence that may impact attitude, the researchers were interested in testing known influencers of attitude based on ELM, thus hierarchical regression analysis was the better choice (Rawlings, Pantula, \& Dickey, 1998). Additionally, the researchers did not want to introduce the additional limitations associated with stepwise regression into their results (Rawlings et al., 1998). The models were tested in an order 
reflective of the flow of ELM. The communication treatment variable was dummy coded and the historically picturesque treatment was treated as the control (Field, 2013).

\section{Results}

Nearly half of the respondents were male and just over half of the respondents were female (Table 1). The majority of respondents were between 20 and 59 years old. Most respondents made less than $\$ 74,999$. Just over $25 \%$ of respondents had some college education, while just over $23 \%$ had a high school education or 4-year college degree. The majority of respondents were white.

\section{Table 1}

Respondent demographics

\begin{tabular}{|c|c|c|}
\hline & $f$ & $\%$ \\
\hline \multicolumn{3}{|l|}{ Gender } \\
\hline Male & 508 & 48.4 \\
\hline Female & 541 & 51.6 \\
\hline \multicolumn{3}{|l|}{ Age } \\
\hline $20-29$ & 198 & 18.9 \\
\hline $30-39$ & 187 & 17.8 \\
\hline $40-49$ & 202 & 19.3 \\
\hline $50-59$ & 195 & 18.6 \\
\hline $60-69$ & 136 & 13.0 \\
\hline $70-79$ & 78 & 7.4 \\
\hline 80 and older & 52 & 5.0 \\
\hline \multicolumn{3}{|l|}{ Income } \\
\hline$\$ 24,999$ or less & 269 & 25.6 \\
\hline$\$ 25,000-\$ 49,999$ & 329 & 31.4 \\
\hline$\$ 50,000-\$ 74,999$ & 212 & 20.2 \\
\hline$\$ 75,000-\$ 149,999$ & 190 & 18.1 \\
\hline$\$ 150,000-\$ 249,999$ & 33 & 3.1 \\
\hline$\$ 250,000$ or more & 16 & 1.6 \\
\hline \multicolumn{3}{|l|}{ Education } \\
\hline Less than high school & 24 & 2.3 \\
\hline High school graduate (includes GED) & 251 & 23.9 \\
\hline Some college, no degree & 282 & 26.9 \\
\hline 2-year college degree & 113 & 10.8 \\
\hline 4-year college degree & 247 & 23.5 \\
\hline Graduate or professional degree & 133 & 12.7 \\
\hline \multicolumn{3}{|l|}{ Race/Ethnicity } \\
\hline American Indian or Alaska Native & 22 & 2.1 \\
\hline Black or African American & 93 & 8.8 \\
\hline Asian or Pacific Islander & 44 & 4.2 \\
\hline White & 892 & 85.0 \\
\hline Other & 23 & 2.1 \\
\hline Hispanic & 96 & 9.2 \\
\hline
\end{tabular}


Objective 1: Describe respondents' prior beliefs, personal involvement, knowledge, and attitude toward livestock care and use.

The respondents held prior beliefs that reflected a favorable view of various livestock care and use practices $(M=9.30, S D=2.235$; scale ranged from $0-11)$. Participants demonstrated neutral personal involvement with livestock topics $(M=7.083, S D=2.145$; scale ranged from 0 12). More than $80 \%$ of respondents answered three or less knowledge questions correctly (8 total knowledge questions). Overall, respondents had a mean attitude score of 3.61 ( $S D=.95$; scale ranged from 1 - 5). Those respondents exposed to the modern reality treatment $(n=534)$ had slightly lower attitudes $(M=3.52, S D=.94)$ than those respondents exposed to the historically picturesque treatment $(n=515 ; M=3.70, S D=.95)$.

Objective 2: Compare predictive models to determine which ELM variables and which persuasive communication treatment have the greatest influence on attitude.

Objective two was evaluated using a hierarchical regression analysis to determine which ELM variables had the greatest influence on attitude toward livestock care and use. The models were tested in an order reflective of the flow of ELM. Consistent with ELM, the persuasive communication treatment served as a predictor of attitude in the first model (Table 2). The first model was significant $(F(1,843)=12.369, p=.000)$ and accounted for $1.4 \%$ of the variance $\left(R^{2}=\right.$ $.014)$ in attitude toward livestock care and use. The communication treatment was a significant predictor for the first model $(b=-.230, p=000)$, meaning attitude decreased by .230 for those who received the modern reality treatment as compared to the historically picturesque treatment.

The persuasive communication treatment and personal involvement (motivation) were the predictors for the second model (Table 3), following the flow of variables as presented in ELM (Petty et al., 2009). This model was also significant, $F(2,842)=13.714, p=.000$. The second model accounted for $3.2 \%$ of the variance in attitude. The change in $R^{2}$ between the first and second model was .017 ( $F$ Change $=14.856, p=.000$ ). The communication treatment and personal involvement variables were both significant predictors in this model $(b=-.250, p=.000 ; b=.059$, $p=.000)$. Therefore, attitude decreased by .250 for those who received the modern reality treatment as compared to the historically picturesque treatment and increased by .059 for each increase in personal involvement.

Three predictors were used in the third model, communication treatment, personal involvement (motivation), and prior beliefs (nature of processing), following ELM (Petty et al., 2009). The results indicated that the third model was also significant, $F(3,841)=33.755, p=.000$ (Table 4 ). The $R^{2}$ value was .107 , implying that $10.7 \%$ of the attitude variance toward livestock care and use could be explained through this model. The change in $R^{2}$ was .076 ( $F$ Change $=$ $74.541, p=.000)$. The communication treatment and prior beliefs were significant predictors of attitude $(b=-.223, p=.000 ; b=.128, p=.000)$. However, personal involvement was no longer a significant predictor. Attitude decreased by .223 for those who received the modern reality treatment as compared to the historically picturesque treatment and increased by .128 for each increase in prior beliefs. 
Table 2

Hierarchical regression analysis for ELM variables on attitude toward livestock care and use

\begin{tabular}{lccccccccc}
\hline Variable & \multicolumn{3}{c}{ Model 1 } & \multicolumn{3}{c}{ Model 2 } & \multicolumn{3}{c}{ Model 3 } \\
Constant & $b$ & $t$ & $p$ & $b$ & $t$ & $p$ & $b$ & $t$ & $p$ \\
\hline Communication & -.230 & -3.52 & .000 & -.250 & -3.84 & .000 & -.223 & -3.55 & .000 \\
Treatment & & & & & & & & & \\
Personal Involvement & & & & .059 & 3.85 & .000 & .022 & 1.48 & .139 \\
Prior Beliefs & & & & & & & .128 & 8.458 & .000 \\
\hline
\end{tabular}

\section{Conclusions and Discussion}

This study sought to understand the influence of two images on attitudes toward livestock care and use, using the ELM framework. The variables were considered in an order reflective of the ELM and resulted in the testing of three predictive models through hierarchical regression. The communication treatment was a predictor in each model and was found to be a significant predictor in all three models. The findings suggest that attitudes toward livestock care and use decrease when respondents received the modern reality treatment. The significance of the communication treatment aligns with previous research that found messages with visual elements to have an influence on attitude (Griffin, 2008; Messaris, 1994). Personal involvement was accounted for in the second and third models. Personal involvement was found to be significant in the second model, but not in the third model. This finding may suggest that respondents did not have the motivation to process the message (Petty et al., 2009) and may be explained by previous literature that posits "most people are not motivated or highly involved with animal agriculture" (Abrams \& Meyers, 2012, p. 64). Additionally, the level of motivation expressed through personal involvement may not have been high enough to consistently influence attitude. The personal involvement results may be further explained by the modest reliability of the scale or the way personal involvement was operationalized in this study. The personal involvement scale items asked about physical and actionable personal involvement, the results may have different if emotional involvement was assessed instead. Prior belief was the final variable considered and was accounted for in the final model. Prior belief was found to be a significant predictor of attitude, suggesting that initial attitudes were influencing respondents' likelihood to retain their initial attitude or process the message peripherally, per ELM (Petty et al., 2009).

Based on the results of this study, the lack of personal involvement significance in the final model and low knowledge levels suggests, according to ELM, that most respondents likely processed the persuasive communication peripherally due to minimal motivation and ability. According to ELM, some respondents may have also retained their initial attitude. The likely peripheral processing is consistent with prior research examining ELM within the agricultural industry (Frewer et al., 1997; Gore et al., 2008; Goodwin, 2013; Veberke, 2005). The lack of personal involvement significance in the final model also supports previous literature suggesting that when involvement is low, images serve as peripheral cues (Lazard \& Atkinson, 2015).

The third model accounted for the greatest amount of variance; however, the model only explained $10.7 \%$ of the variance. There is still a lot of variance that is unaccounted for by the present model. It is possible that knowledge would have explained some of the unaccounted variance, if the assumptions of the variable would have been met. Additional ELM variables such as need for cognition, distraction, repetition, and argument quality could also contribute to 
explaining the additional variance. Additionally, other influencing factors or personal characteristics may have been more salient for this audience. The images themselves may also explain some of variance in attitude. Due to the decrease in attitudes observed among the group that received the modern reality treatment, it is thought that the image may have been culturally incongruent to the respondents' expectations for "cage-free housing" (Ham et al., 2015). The incongruence may have caused skepticism or even activated persuasion knowledge causing the decrease in attitudes among this group (Ham et al., 2015). Cognitive dissonance may also explain the findings associated with the modern reality treatment. However, further research is required to determine the validity of these assumptions.

Because prior beliefs and the communication treatment were significant predictors in the final model, communicators should focus on message creation that aligns with audience's beliefs and provide exposure to value-driven communication. While the results do not definitively suggest which image to use or how much to show, they do provide findings that should be used by communicators to provoke discussion and make informed decisions about visual communication in the livestock industry. The impact of the communication treatment on attitudes suggests that communicators should carefully select images when crafting messaging. Attitude scores decreased when respondents were exposed to the modern reality treatment. Thus, historically picturesque communication messages will result in more positive attitudes. However, communicators in the livestock industry should weigh the risks and benefits to communicating with images that are not reflective of reality (Carroll, 1991; Jaques, 2012; Rawlins, 2008). The livestock industry should also consider engaging in collaborative efforts to work toward educating the public on modern realities of livestock production so that modern images and understanding of those images become more familiar to consumers. If familiarity with modern images of livestock production is improved, the results of this study may be different. Perhaps another consideration is to select images that show a balance between stereotypes and reality by removing social stimuli as suggested by Berg and Söderlund (2013). Removing "cage free" from the descriptions and reframing the modern reality image to be shot at floor level free from the stacks of cages and glare of the artificial light may remove social stigmas at work in these images, but further research is needed to confirm this idea.

The tendency for agricultural information to be processed peripherally, suggests that communicators should be highly cognizant of peripheral cues and social stimuli embedded within messages to ensure the intended processing of information. For these reasons, practitioners are encouraged to conduct thorough audience analyses and test messages prior to their release.

More questions and variables of interest have been discovered as a result of this study and therefore several recommendations for further research have been made. This study was unable to utilize knowledge as an ability factor. Future research should work to refine the knowledge variable as well as examine other variables to gain a more holistic view of consumers' progression through ELM when assessing information related to livestock care and use. It is recommended that further research be conducted to determine if cognitive dissonance and persuasion knowledge impacted the processing of the images. Researchers should use qualitative methods such as thought-listing procedures to gain better understanding of how the respondents processed the communication treatments. This procedure would allow for further conclusions about the processing route taken by participants and provide further insight to the selection and use of visual and text-based messages. Researchers should also monitor the communication and research of other industries with poor image perception. Methods and techniques of these industries may be applicable to an agricultural context. Additionally, further studies should explore if similar results 
would occur given different images, repeated exposure, and a different agricultural context. Finally, perceptions of a historical time-lapse image may provide a greater understanding of how processing evolves while individuals view a production system that has changed overtime. 


\section{References}

Abrams, K. \& Meyers, C. (2012). From opposite corners: Comparing persuasive message factors and frames in opposing organizations' websites. Journal of Applied Communications, 96(1), 54-67. https://doi.org/10.4148/1051-0834.1150

Animal Plant and Health Inspection Service. (2010). Overview of U.S. livestock, poultry, and aquaculture production in 2010 and statistics on major commodities. Retrieved from https://www.aphis.usda.gov/animal_health/nahms/.../Demographics2010_rev.pdf

Ary, D., Jacobs, L. C., Sorensen, C. K., \& Walker, L. (2014). Introduction to research in education $\left({ }^{\text {th }}\right.$ ed.). Belmont, CA: Cengage Learning

Baker, R., Brick, J., Bates, N., Battaglia, M., Couper, M., Dever, J., ... Tourangeau, R. (2013). Summary report of the AAPOR task force on non-probability sampling. Journal of Survey Statistics and Methodology, 1(2), 90-143. doi:10.1093/jssam/smt008

Bell, E., Norwood, F. B., \& Lusk, J. L. (2017). Are consumers willfully ignorant about animal welfare? Animal Welfare, 26, 399-402. doi:10.7120109627286.26.4.399

Berg, H., \& Söderlund, M. (2013). Face value: Images of headless decorative models increase consumer identification and product attitudes. In S. Rosengren, M. Dahlen, S. Okazaki (eds.). Advances in advertising research (Vol. IV). Springer Fachmedien Wiesbaden.

Beulens, A. J. M., Broens, D., Folstar, P., \& Hofstede, G. J. (2005). Food safety and transparency in food chains and networks. Food Control, 16, 481-486. doi: 10.1016/j.foodcont.2003.10.010

Cacioppo, J. T., Petty, R. E., Kao, C. F., \& Rodriguez, R. (1986). Central and peripheral routes to persuasion: An individual difference perspective. Journal of Personality and Social Psychology, 51(5), 1032-1043. doi:10.1037/0022-3514.51.5.1032

Carroll, A. B. (1991). The pyramid of corporate social responsibility: Toward the moral management of organizational stakeholders. Business Horizons, 34(4), 39-48. doi: 10.1016/0007-6813(91)90005-G

Dietrich, C. N. (2016). How Did We Get Here? Understanding Consumers' Attitudes Toward Modern Agriculture Practices (Master's Thesis). Retrieved from the Ohio State University.

Duncan, D. W., \& Broyles, T. W. (2006). A comparison of student knowledge and perceptions toward agriculture before and after attending a governor's school for agriculture. NACTA Journal, 50(1), 16-21. Retrieved from http://www.nactateachers.org/journal.html

Field, A. (2013). Discovering statistics using IBM SPSS statistics (4th ed.). Thousand Oaks, CA: SAGE 
Frewer, L. J., Howard, C., Hedderley, D., \& Shepherd, R. (1997). The elaboration likelihood model and communication about food risks. Risk Analysis, 17(6), 759-770. doi: 10.1111/j.1539-6924.1997.tb01281.x

Glaze, C., Edgar, L., Buck, E., \& Rutherford, T. (2013). Visual communications: An analysis of university students' perceptions of rural America based on selected photographs. Journal of Applied Communication, 97(1), 1-16. https://doi.org/10.4148/1051-0834.1100

Goodwin, J. N. (2010). Knowledge and perceptions of agriculture practices and legislation related to social influences as predictors of voting on agriculture policy (Masters Thesis). Retrieved from The OhioLink http://rave.ohiolink.edu/etdc/view?acc_num=osu1274705418

Goodwin, J. N. (2013). Taking down the walls of agriculture: Effect of transparent communication and personal relevance on attitudes and trust within the Elaboration Likelihood Model (Doctoral Dissertation). Retrieved from the University of Florida. http://ufdcimages.uflib.ufl.edu/UF/E0/04/53/18/00001/GOODWIN_J.pdf

Gore, M. L., Knuth, B. A., Scherer, C. W., \& Curtis, P. D. (2008). Evaluating a conservation investment designed to reduce human-wildlife conflict. Conservation Letters, 1(3), 136145. Retrieved from http://onlinelibrary.wiley.com/journal/10.1111/(ISSN)1755-263X

Griffin, M. (2008). Visual competence and media literacy: Can one exist without the other? Visual Studies, 23(2), 113-129. doi:10.1080/14725860802276255

Guttman, L. (1950). The basis for scalogram analysis. In S. A. Stouffer et al. (Eds.), Measurement and prediction. Princeton: Princeton University Press.

Ham, C., Nelson, M. R., Das, S. (2015). How to measure persuasion knowledge. International Journal of Advertising, 34(1), 17-53. http://dx.doi.org/10.1080/02650487.2014.994730

Jaques, T. (2012). Is issue management evolving or progressing towards extinction? Public Communication Review, 2(1), 35-44. Retrieved from http://epress.lib.uts.edu.au/journals/index.php/pcr

Lazard, A. \& Atkinson, L. (2015). Putting environmental infographics center stage: The role of visuals at the Elaboration Likelihood Model's critical point of persuasion. Science Communication, 37(1), 6-33. doi: 10.1177/1075547014555997

Lundy, L. K., Ruth, A. M., \& Park, T. D. (2007). Entertainment and agriculture: An examination of the impacts of entertainment media on perceptions of agriculture. Journal of Applied Communications, 91(1), 65-79. https://doi.org/10.4148/1051-0834.1257

Messaris, P. (1994). Visual "literacy": Image, mind, \& reality. Boulder, CO: Westview Press 
Petty, R. E., Brinol, P., \& Priester, J. R., (2009). Mass media attitude change: Implications of the elaboration likelihood model of persuasion. In J. Bryant, \& M. B. Oliver (Eds.), Media effects: Advances in theory and research (pp. 125-164). New York: Routledge.

Rawlins, B. (2008). Give the emperor a mirror: Toward developing a stakeholder measurement of organizational transparency. Journal of Public Relations Research, 21(1), 71-99. doi: $10.1080 / 10627260802153421$

Rawlings, J. O., Pantula, S. G., Dickey, D. A. (1998). Applied regression analysis: A research tool $\left(2^{\text {nd }}\right.$ ed. $)$. New York: Springer.

Specht, A. R., \& Beam, B. W. (2015). Prince farming takes a wife: Exploring the use of agricultural imagery and stereotypes on ABC's The Bachelor. Journal of Applied Communications, 99(4), 1-14. https://doi.org/10.4148/1051-0834.1055

Specht, A. R., McKim, B. R., \& Rutherford, T. (2014). A little learning is dangerous: The influences of agricultural literacy and experience on young people's perceptions of agricultural images. Journal of Applied Communications, 98(3), 1 - 11. https://doi.org/10.4148/1051-0834.1086

Sterk, R. (2017, November 2). USDA reports record meat production. Meat + Poultry. Retrieved from http://www.meatpoultry.com/articles/news_home/Business/2017/11/USDA_reports_reco rd_meat_produ.aspx

Taylor, R. E., \& Field, T. G. (2004). Scientific farm animal production (8th ed.). Saddle River, NJ: Pearson Education, Inc.

Vance, A. (Editor). (2012, April 16). Grandin: Finding balance between science and perception necessary [Audio podcast]. Retrieved from http://www.feedstuffs.com/ME2/dirmod.asp?sid=F4D1A9DFCD974EAD8CD5205E15C $1 \mathrm{CB} 42 \& \mathrm{~nm}=$ Breaking+News \& type $=$ news \& $\bmod =\mathrm{News} \& \mathrm{mid}=\mathrm{A} 3 \mathrm{D} 60400 \mathrm{~B} 4204079 \mathrm{~A} 76$ C4B1B129CB433\&tier=3\&nid=C1B8439AA22E44C09B3735FC97ED8A14

Verbeke, W. (2005). Agriculture and the food industry in the information age. European Review of agricultural Economics, 32(3), 347-368. doi: 10.1093/eurrag/jbi017

Weatherell, C., Tregear, A., \& Allinson, J. (2003). In search of the concerned consumer: UK public perceptions of food, farming and buying local. Journal of Rural Studies, 19(2), 233-244. doi:10.1016/S0743-0167(02)00083-9

Zhou, L., Poon, P., \& Wang, H. (2015). Consumers' reactions to global versus local advertising appeals: A test of culturally incongruent images in China. Journal of Business Research, 68(3), 561-568. https://doi.org/10.1016/j.jbusres.2014.09.006 
Dr. Joy Rumble is an Assistant Professor of Agricultural Communication in the Department of Agricultural Communication, Education, and Leadership at the Ohio State University.

Tiffany M. Rogers-Randolph is a doctoral candidate in the Department of Agricultural Education and Communication at the University of Florida.

Dr. Emily Buck is a Professor of Agricultural Communication in the Department of Agricultural Communication, Education, and Leadership at the Ohio State University.

This work was supported by the UF/IFAS Center for Public Issues Education and contributed to USDA National Institute of Food and Agriculture, Hatch project \#1003955.

A version of this manuscript was presented at the 2018 Association for Communication Excellence in Agriculture, Natural Resources, and Life and Human Sciences Conference in Scottsdale, AZ. 